\title{
Economic Evaluation of the Breeding Goal for Norwegian Red Dairy Cattle
}

\author{
G. Steine, ${ }^{\star} †$ D. Kristofersson, $\neq \S$ and A. G. Guttormsen $\S^{1}$ \\ *AKVAFORSK, Institute of Aquaculture Research AS, PO Box 5010, N-1432 Ås, Norway \\ †Department of Animal and Aquacultural Sciences, Norwegian University of Life Sciences, N-1432 Ås, Norway \\ łInstitute of Economic Studies, University of Iceland, Aragata 14, 101 Reykjavík, Iceland \\ $\S$ Department of Economics and Resource Management, Norwegian University of Life Sciences, PO Box 5003, N-1432 Ås, Norway
}

\begin{abstract}
In this paper, a translog profit function was applied to estimate the economic values of the traits included in the breeding goal for Norwegian Red dairy cattle. The following 10 traits are included in the breeding goal: milk, meat, mastitis resistance, fertility, calving difficulties, stillbirths, other diseases, udder, temperament, and legs. An empirical implementation that locally approximates the unknown true profit function was suggested and estimated, taking farm heterogeneity into account. The model was applied to a panel data set of 3,259 Norwegian dairy farms over the period 1999 to 2003. Panel data, also called longitudinal or crosssectional time-series data, are multiple cases (cows, farms, countries, etc.) observed over 2 or more time periods. The data set consisted of farm-level data, including production and economic data from the farm and the estimated breeding values for each cow's sire. The estimated economic values make it possible to test whether genetic selection has been profitable for the farmer, and the extent to which the currently used economic values were optimal during the period 1999 to 2003. Although the translog profit function is quite flexible, it is rather complex, and a simplified version of the model, a Cobb-Douglas profit function, was also estimated. However, the hypothesis that this simpler function adequately describes the data compared with the full translog model was rejected. Further, the hypothesis that the estimated breeding values are profit neutral was rejected (i.e., the hypothesis that there are no interactions between input and output prices on one hand and estimated breeding values on the other). These results indicated that selection not only leads to a parallel shift in profits, but also to changes in input use. Seven of the 10 traits had a significant effect on the farmers' profit. The 3 traits that were not significant
\end{abstract}

Received November 9, 2006.

Accepted September 7, 2007.

${ }^{1}$ Corresponding author: atle.guttormsen@umb.no were calving difficulty, stillbirth, and other diseases. The results showed that the breeding program for Norwegian Red cattle has been fairly successful in improving farmers' profits. However, a slight modification of the breeding goal, such as a reduction in the weights for stillbirths and other diseases and an increase in the weights for meat and temperament, would increase farm profits.

Key words: breeding goal, production function, panel data

\section{INTRODUCTION}

The objective of most animal breeding programs is to improve the profitability of the animal. This often involves simultaneous improvements in multiple traits. Hazel (1943) discussed the problem of optimal weighting of each trait in a total merit index and argued that such weights should be economic, portraying the economic importance of each trait for the farmer. Hazel (1943) defined economic value in breeding as "the amount by which profit may be expected to increase for each unit improvement in that trait." This was later modified by McArthur (1987) to "the amount by which net profit of the optimal policy may be expected to increase for a unit improvement in that trait." Optimal policy indicates an assumption about the behavior of the farmer. It implies that the farm does not use wasteful production methods; in other words, the farmer tries to produce as much output as viable given his or her inputs, animals, and technology. This is not the same as maximizing output, because output could potentially be increased by using inputs that cost more than the value of increased output. That would be wasteful production. Instead, the behavioral assumption must take prices of inputs and outputs into account. It is widely accepted in the economic literature that the assumption of optimal policy is synonymous with assuming that the farmer is maximizing his or her profit. The gains from running a farm are monetary, and a nonwasteful production method is therefore a production method 
that maximizes the monetary gains-the profits. This means that the farmer bases his or her production decision on both the technology at hand, the characteristics of the animals, and the prices of inputs and outputs. The farmer may choose to change his or her production if the animals improve. However, he or she may also change the production if prices of inputs or outputs change. Both factors are closely related and must be taken into account in the modeling to ensure that the policy is truly optimal. The explicit use of behavioral assumptions marked a paradigm shift in the empirical economic literature away from the estimation of technical relationships, such as production functions, toward the estimation of derived functions, such as cost functions, expenditure functions, and profit functions. Conventionally, economic values have been estimated by using 1) the partial differentials of a profit equation that technically describes the profit of the production system as a linear function of genetic change in component traits by using simulation (e.g., Brascamp et al., 1985; Smith et al., 1986; de Vries, 1989); or 2) a model of genetic improvement based on economic production theory in the estimation of economic values for livestock improvement programs (e.g., Amer and Fox, 1992; Amer et al., 1994; Melton et al., 1994). In this paper, the methodology of empirical economic estimation based on functions derived from the profit-maximization problem of the farmer was applied in estimating economic values in dairy cattle.

It is of considerable interest for breeders and farmers to verify the economic values a posteriori by using data from actual farms. Breeding is costly, and it is of the utmost importance for farmers to secure the most profitable selection strategy by choosing either animals or breeds. A method for estimating the effects of selection on profits is suggested in this analysis, using data from individual farms. Economic theory allows one to construct models from data on prices and quantities for inputs and outputs (Chambers, 1988) and the EBV of the animals, with the assumption that farmers maximize profits. The results from such estimation with historical data can then be used to test whether current economic values actually maximize profits.

Several challenges arise when estimating the effects of breeding on profits. First, the mathematical relationship between traits and profits has to be approximated correctly. Because little is known about the actual mathematical relationship between traits and profits, a flexible functional form is used, which approximates the unknown true relationship. The method requires a rich and reliable data set of farm-level data. Second, there is considerable land and labor heterogeneity in farm-level data that needs to be taken into account if estimates are applied to a "representative farm." Third, the effect on profits of genetic changes in single traits is small, and sufficient power must be obtained for the analysis. This can be achieved with either very precise data or numerous observations, emphasizing the importance of databases where economic and genetic information is available.

Evaluation of breeding programs for the Norwegian Red (NR) breed is of special interest for several reasons. First, Geno, the breeding organization that breeds the NR, has for many years (i.e., since the 1970s) emphasized the importance of a broad breeding goal, and as many as 10 traits are included in the current breeding goal. Second, Geno has focused more on health and fertility than have many other breeding organizations. Currently, for example, mastitis resistance, fertility, and other diseases account for more than $40 \%$ of the breeding objective. Therefore, it is of interest to evaluate whether these choices have increased farmers' profits.

This paper makes 3 main contributions. First, a model of economic value is derived from the profit-maximization problem of the farmer by using the standard methodology of empirical economic modeling, which is based on the assumption about how farmers run their farms. Second, an empirical model that locally approximates the true unknown function and takes farm heterogeneity into account is proposed. Third, the model is applied to farm-level panel data on Norwegian dairy farms, and the economic values of the 10 traits that are currently included in the breeding goals for the NR are estimated. This allows tests of whether breeding increases farm profits and whether the currently used economic values are historically optimal.

\section{MATERIALS AND METHODS}

\section{Theoretical Background}

Here we present a simplified description of an economic model based on the assumption that the farmer is profit maximizing. Although the model is simple, it gives a clear picture of the way such models are derived. When a farm produces a single output, $y$, from a single input, $x$, the relationship between the output and the input can be described by a production function, $y=$ $f(x)$. Further, assume profit-maximizing farmers and that the production function is affected by the EBV, $b$, of the animals on the farm, that is, $y=f(x \mid b)$. The production function is assumed to have the following properties:

$$
\frac{\partial f(x \mid b)}{\partial x}>0, \frac{\partial^{2} f(x \mid b)}{\partial x^{2}} \leq 0, \frac{\partial f(x \mid b)}{\partial b}>0 .
$$


The first derivative of the production function with respect to input is greater than zero, and the second derivative is equal to or less than zero. This implies that the curve of factor demand slopes downward. The sign of the second-order derivative is justified by the rule of diminishing marginal product, stating that increasing one input results in smaller output increases, all other things being equal. Given some fixed resources (other inputs, investments), production must be limited and cannot increase indefinitely. The farmer's problem is then to maximize profit, $\pi$, given the breeding material of the livestock and the prices for inputs and outputs:

$$
\max _{x}[p f(x \mid b)-w x],
$$

where $p$ is the price of the output and $w$ is the price of the input. The prices, $w$ and $p$, as well as the EBV, $b$, are exogenous, that is, out of the farmers' control. The first-order condition for this problem is as follows:

$$
\begin{gathered}
\frac{\partial \pi}{\partial x}=p \frac{\partial f(x \mid b)}{\partial x}-w=0 \\
p \frac{\partial f(x \mid b)}{\partial x}=w \text { or } \frac{\partial f(x \mid b)}{\partial x}=\frac{w}{p} .
\end{gathered}
$$

This is a classical result in economics, where optimal profit is reached at the point where marginal revenue equals marginal cost. This expression also implies that optimal profit is reached where the slope of the production function equals the ratio between the input and output price. This classical result shows that changes in input prices relative to output prices change the optimal production output of the farmer. It also shows the same potential for changes in EBV, as long as EBV affects the marginal product. Two separate ways may therefore exist by which EBV affects profits. First, there is a direct effect of selection, increasing the amount of output that can be produced by using the same amount of inputs, as stated in equation [1]. Second, there is an indirect effect of the change in EBV on the slope of the production function. That would then lead to an adjustment of input use to satisfy the profit-maximizing condition in equation [3].

Assume further that this first-order condition can be solved for the optimal input, $x^{*}$, yielding the input demand function:

$$
x^{*}=x^{*}(p, w, b) .
$$

The profit function is obtained by inserting the input demand function back into the original problem. The profit function, which is a so-called value function, gives the optimal profit that the farm can obtain at any given input and output price and EBV, given that the farmer maximizes profit:

$$
\pi^{*}=p f\left[x^{*}(p, w, b) \mid b\right]-w x^{*}(p, w, b)=\pi^{*}(p, w, b) .
$$

Modeling in terms of the profit function in equation [5] has a significant advantage over modeling in terms of the production function, $y=f(x \mid b)$, because the profit function can be used to predict both the direct and indirect effects of changes in EBV on profits. Neglecting the indirect effects could lead to misleading results, because no relationship is assumed between prices and EBV, where the general model clearly implies that such a relationship may exist.

Estimating a value function on the basis of the exogenous variables and the assumption of profit-maximizing behavior is the most common approach to empirical estimation in applied economic research. This is a much simpler procedure than estimating the primal problem and solving for the profit-maximizing conditions.

The profit function has several known properties: it is nondecreasing in output prices, nonincreasing in input prices, and homogeneous to degree one in output and input prices. This final property, homogeneity of degree one, simply implies that if all prices increase by the same relative amount (e.g., general inflation), then profit must necessarily increase by the same relative amount. Moreover, the input demand function (equation [4]) and the output supply function can be derived directly from the profit function (equation [5]) by using Hotelling's lemma:

$$
\begin{gathered}
\frac{\partial \pi^{*}(p, w, b)}{\partial p}=s^{*}(p, w, b) \\
\text { and } \frac{\partial \pi^{*}(p, w, b)}{\partial w}=-x^{*}(p, w, b),
\end{gathered}
$$

where the function $s^{*}$ is the output supply function. Hotelling's lemma was derived by the application of the envelope theorem (e.g., Chambers, 1988) to the profitmaximization problem.

Given the assumptions in equation [1], the profit function is nondecreasing in the EBV. Although genetic selection has not been extensively discussed in the economic literature, it can be viewed as a type of technological change (Melton et al., 1979; Kerr, 1984). Fortunately, technological change has been the subject of extensive economic literature (e.g., Binswang, 1974; Huffman and Evenson, 2001). We have assumed that selection affects the optimization of the farm in the same way as technological change is generally assumed 
to affect production. There is the direct effect of higher production with the same amount of inputs and the indirect effects on the shape of the production function. If the technological change has no effect on the shape of the production function, then the technological change is called profit neutral. Both profit-neutral and non-profit-neutral technological change are shown in Figure 1.

For a profit-neutral technology, the profit function in equation [5] can be rewritten as

$$
\pi^{*}=g(b) \pi^{*}(p, w)
$$

where $g(b)$ is a function of EBV. This is obviously a testable hypothesis in empirical models.

In the context of the profit function, the optimal economic value $(E V)$ is simply the partial derivative of the profit function in terms of the EBV. In terms of the general profit function based on the average of all herds, as derived in equation [6], this is as follows:

$$
E V=\frac{\partial \pi^{*}(p, w, b)}{\partial b}
$$

\section{Empirical Estimation}

Two major challenges are involved in estimating the profit function in equation [5] or [7]. The first involves the functional form of the profit function. The second involves the treatment of unobservable heterogeneity in land, labor, and capital inputs among farms. Applied economists have long been aware of the difficulty of identifying the true form of these and other functions. This has led to the general use of flexible functional forms, such as Taylor expansions, that are able to locally approximate any function. Among the more popular forms in production economics is the translog functional form first suggested by Christensen et al. (1973), comprising a second-order approximation of an unknown log-log relationship. A translog approximation of the profit function of equation [7] for $K$ traits, $M$ inputs, and $N$ outputs is then as follows:

$$
\begin{gathered}
\ln (\pi)=\alpha_{0}+\sum_{k=1}^{K} \phi_{k} \ln \left(b_{k}\right)+\sum_{k=1 i=1}^{K} \sum_{i=1}^{N} \phi_{k i} \ln \left(b_{k}\right) \ln \left(p_{i}\right) \\
+\sum_{k=1}^{K} \sum_{i=1}^{M} \phi_{k(i+N)} \ln \left(b_{k}\right) \ln \left(w_{i}\right)+\sum_{i=1}^{N} \beta_{i} \ln \left(p_{i}\right) \\
+\sum_{i=1}^{M} \beta_{i+N} \ln \left(w_{i}\right)+\frac{1}{2}\left[\sum_{i=1}^{N} \sum_{j=1}^{N} \gamma_{i j} \ln \left(p_{i}\right) \ln \left(p_{j}\right)\right. \\
\left.+\sum_{i=1 j=1}^{N} \sum_{i=1}^{M} \gamma_{i(j+N)} \ln \left(p_{i}\right) \ln \left(w_{j}\right)+\sum_{i=1}^{M} \sum_{j=1}^{M} \gamma_{(i+N)(j+N)} \ln \left(w_{i}\right) \ln \left(w_{j}\right)\right]
\end{gathered}
$$

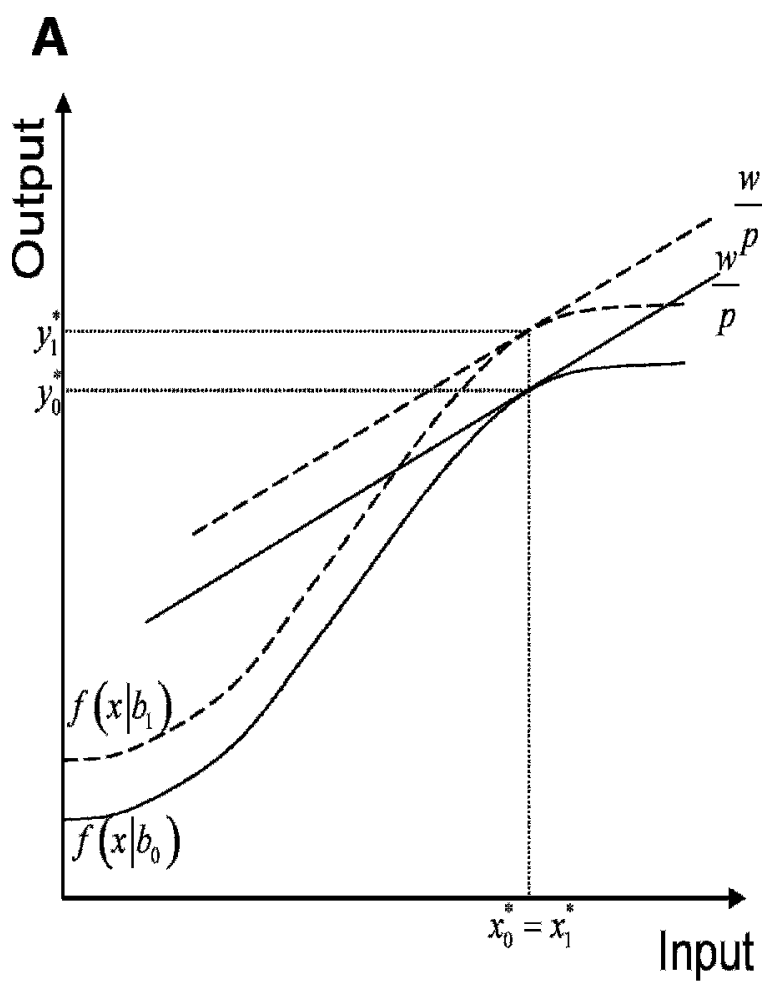

B

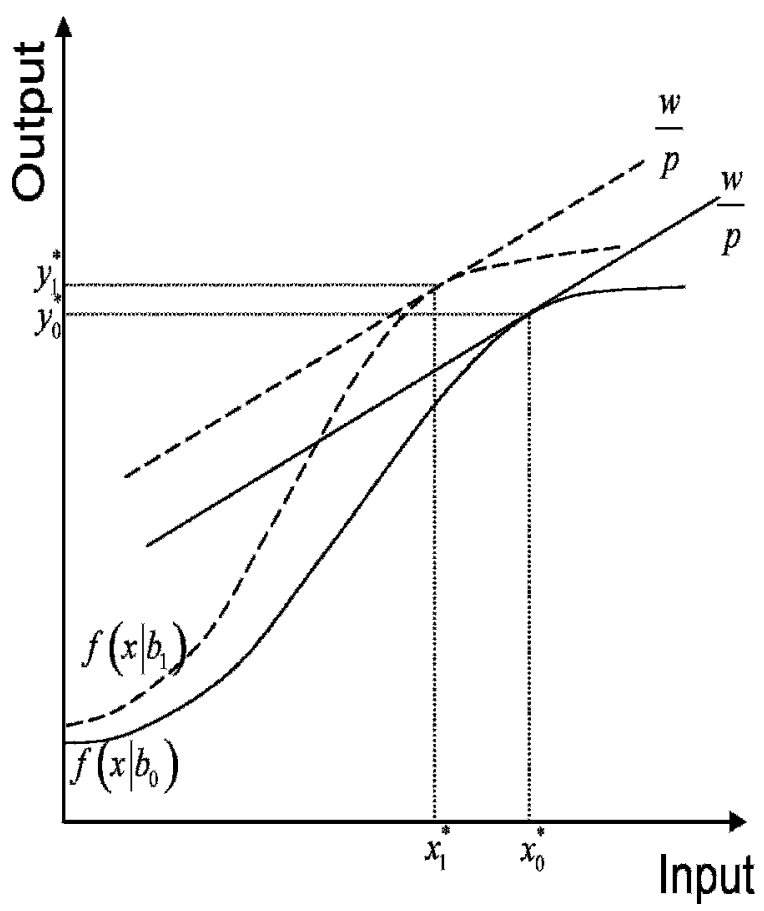

Figure 1. (A) Profit-neutral and (B) non-profit-neutral technological change. The subscript 0 indicates the EBV before a change, and the subscript 1 indicates the EBV after a change, where $x$ is the amount of input and $y$ is the amount of output; $f(x \mid b)$ is the production function, where $b$ is the EBV; and $\frac{w}{p}$ is the ratio between input price $(w)$ and output price $(p)$. 
The profit-neutral profit function is a simplified version of equation [9], where $\phi_{k i}=0 \forall k, i$. Further, the Cobb-Douglas profit function, which is profit neutral by assumption, is obtained by $\gamma_{k i}=0 \forall i, j$ and $\phi_{k i}=0 \forall$ $k, i$, as

$$
\begin{aligned}
\ln (\pi)=\alpha_{0} & +\sum_{k=1}^{K} \phi_{k} \ln \left(b_{k}\right)+\sum_{i=1}^{N} \beta_{i} \ln \left(p_{i}\right) \\
& +\sum_{i=1}^{M} \beta_{i+N} \ln \left(w_{i}\right) .
\end{aligned}
$$

Both the profit-neutral translog function and the CobbDouglas profit function are special cases of the general translog in equation [9].

The parameter estimates for the economic value are the partial derivative of equation [9] with respect to the EBV. The expression for the economic value for trait $k$ is given by

$$
\begin{gathered}
\frac{\partial \pi}{\partial b_{k}}=\frac{\partial \pi}{\partial \ln (\pi)} \frac{\partial \ln (\pi)}{\partial \ln \left(b_{k}\right)} \frac{\partial \ln \left(b_{k}\right)}{\partial b_{k}}= \\
\frac{\pi}{b_{k}}\left(\phi_{k}+\sum_{i=1}^{N} \phi_{k i} \ln \left(p_{i}\right)+\sum_{i=1}^{M} \phi_{k(i+N)} \ln \left(w_{i}\right)\right) .
\end{gathered}
$$

A point estimate can be obtained by evaluating the derivative at a fixed point, for example, the expected value of input and output prices, and profits. By centralizing the input and output prices, that is, by subtracting the expected value of each variable from it, the interpretation of the parameter estimates can be simplified with respect to economic value. For centralized input and output prices, the expression in equation [11] at the point of centralization simplifies to

$$
\frac{\partial \pi}{\partial b_{k}}=\frac{\pi}{b_{k}} \phi_{k}
$$

The first-order parameter, $\phi_{k}$, is now easily interpretable with respect to the economic value. The parameter $\phi_{k}$ measures the percentage change in profit for an overall increase in herd EBV of one unit from its mean. A parameter estimate of 0.5 implies that profit will increase with $0.5 \%$ if EBV increases by one unit from its mean. The economic value evaluated at the point of centralization for expected profits and EBV is then given by

$$
E V=\frac{\bar{\pi}}{\bar{b}_{k}} \phi_{k}
$$

where $\bar{\pi}$ stands for expected profits and $\bar{b}_{k}$ is the mean EBV.
The hypothesis that EBV has no effect on profits can be stated as a parameter restriction of the form $\phi_{k}=0$, $\phi_{k i}=0 \forall k, i$. Similarly, the hypothesis that the true economic value is some constant $\theta$ can be formulated as a linear restriction of the form $\frac{\partial \pi}{\partial b_{k}}=\theta$.

Homogeneity of degree one implies that $\Sigma_{i} \Sigma_{j} \gamma_{i j}=0$ and $\Sigma_{i} \beta_{i}=1$, and symmetry implies $\gamma_{i j}=\gamma_{j i} \forall i, j$. The terms $\beta$ and $\gamma$ describe the effects of input and output prices on profits, and given equation [6], these are the parameters of the input demand and output supply functions. The number of parameters to be estimated in equation [9] is large, and many observations are needed to achieve identification. This could be accomplished by using a relatively long time series for a single farm; however, technological changes over time make it difficult to assume constant breeding effects. As an alternative, a cross-section of farms could be specified, assuming all farms are the same. However, this is obviously not the case. Casual observation confirms that substantial differences in the quality of land, labor, and capital occur, manifesting themselves as, for example, differences in the chosen scale of operations. Instead, if panel data exist, comprising several cross-sections of the same farms at different points in time, it is possible to take these differences into account by allowing the profit function to vary from farm to farm. Let $\beta$ be the vector of parameters, and $x$ the vector of variables and interactions in equation [9]; that is, let $\mathbf{x}_{l t}$ be the vector for the $l$ th farm in time period $t$ :

$$
\begin{aligned}
\mathbf{x}_{l t}= & {\left[1 \operatorname { l n } \left(b_{1 l t} \ldots \ln \left(b_{K l t}\right) \ln \left(b_{1 l t}\right) \ln \left(p_{1 l t}\right) \ldots \ln \left(b_{K l t}\right) \ln \left(p_{N l t}\right)\right.\right.} \\
& \left.\ldots . .1 / 2 \ln \left(w_{1 l t}\right) \ln \left(w_{1 l t}\right) \ldots 1 / 2 \ln \left(w_{M l t}\right) \ln \left(w_{M l t}\right)\right] .
\end{aligned}
$$

The stochastic version of equation [9] is then given by

$$
\ln \left(\pi_{l t}\right)=\mathbf{x}_{l t} \boldsymbol{\beta}+u_{l}+e_{l t},
$$

for the $l$ th farm in time period $t$, where $\mathbf{x}_{l t}$ is the vector of log-transformed independent variables as defined above. The error in the model has 2 components, one observation specific, $e_{l t}$, and one farm specific, $u_{l}$. These are assumed to capture the variation between years within a farm, $e_{l t} \sim$ iid $N\left(0, \sigma^{2}\right)$, and variation among farms, $u_{l} \sim$ iid $N\left(\mathbf{0}, v^{2} \mathbf{I}\right)$. A single farm is then assumed to be drawn from the distribution of farms, and the parameter vector, $\beta$, defines the profit function for the expected farm.

In this analysis, the farmer is assumed to maximize profits given the prices of 3 outputs, milk $\left(p_{1}\right)$, meat $\left(p_{2}\right)$, and subsidies $\left(p_{3}\right)$, and 2 inputs, forage $\left(w_{1}\right)$ and concentrates $\left(w_{2}\right)$, given the farm's endowment of labor and land. The agricultural sector in Norway is heavily 
subsidized. Farmers receive subsidies for the amount land used as well as for the number of cows. The farmer further incurs veterinary costs, which he or she cannot control, and these are therefore included as a separate quantity variable, $v$. Observations of zero veterinary cost are treated in a separate variable because the logarithm of zero is undefined and denoted with the variable $D$ in model [15]. Estimated breeding values for 10 traits are denoted by $b_{1}$ to $b_{10}$. A translog approximation of the profit function of equation [7] for the $l$ th farm in time period $t$ is as follows:

$$
\begin{aligned}
& \ln \left(\pi_{l t}\right)=\alpha_{0}+\sum_{k=1}^{10} \phi_{k} \ln \left(b_{k l t}\right)+\sum_{k=1 i=1}^{10} \sum_{k i}^{3} \ln \left(b_{k l t}\right) \ln \left(p_{i l t}\right) \\
&+ \sum_{k=1}^{10} \sum_{i=1}^{2} \phi_{k(i+3)} \ln \left(b_{k l t}\right) \ln \left(w_{i l t}\right)+\sum_{i=1}^{3} \beta_{i} \ln \left(p_{i l t}\right) \\
&+\sum_{i=1}^{2} \beta_{i+3} \ln \left(w_{i l t}\right)+\phi_{6} \ln \left(\nu_{l l}\right)+\phi_{7} D_{l t} \\
&+\frac{1}{2}\left[\sum_{i=1}^{3} \sum_{j=1}^{3} \gamma_{i j} \ln \left(p_{i l t}\right) \ln \left(p_{j l t}\right)+\sum_{i=1 j=1}^{3} \sum_{i(j+3)}^{2} \ln \left(p_{i l t}\right) \ln \left(w_{j l t}\right)\right. \\
&\left.+\sum_{i=1 j=1}^{2} \sum_{(i+3)(j+3)}^{2} \ln \left(w_{i l t}\right) \ln \left(w_{j i t}\right)\right]+\delta_{0}\left(\nu_{l t}\right)^{2} \\
&+\sum_{i=1}^{3} \delta_{i} \ln \left(p_{i l t}\right) \ln \left(\nu_{l t}\right)+\sum_{i=1}^{2} \delta_{(i+3)} \ln \left(w_{i l t}\right) \ln \left(\nu_{l t}\right) .
\end{aligned}
$$

The parameters of the model were estimated by using PROC MIXED in SAS, version 8.2. The PROC MIXED procedure facilitates the estimation of random effect models like that defined in equation [14].

\section{Data}

Panel data for 3,259 Norwegian dairy farms from 1999 to 2003 were used in the estimation. Consolidation of farms has become more common in Norway. To avoid errors, farms that exhibited large changes in the scale of production were treated as new producers following these changes.

Price and quantity data were collected through the Norwegian Cow Recording System by the Norwegian milk cooperative, TINE. All farms recorded in the Norwegian Cow Recording System for more than 2 yr over the period 1999 to 2003 were included in the data set. TINE collects economic data directly from the financial statements for each producer. These include data such as costs and quantities for input and output factors, and data on the occurrence of diseases.

The input prices included in the analysis were the prices of concentrates and forage per feed unit. Veterinarian services were, to a large extent, determined by factors over which the farmer has limited control, including the random occurrence of disease. Variables that remain outside the farmer's control will not serve as decision variables in the farmer's optimization problem in function [2], but need to be treated as restrictions in the optimization. Such variables were part of the set of exogenous variables over which the farmer maximizes, and were therefore included in the profit function along with the remaining exogenous variables, such as prices and EBV. The output prices for milk and meat were constructed from the price plus the subsidy per unit. The subsidies per land unit, per management unit, and per dairy cow are summed into a single subsidy price index.

The following 10 traits were included in the estimation: milk, meat, mastitis resistance, fertility, calving difficulties, stillbirth, other diseases, udder, temperament, and legs. These were the same 10 traits included in the breeding goal for the NR. Table 1 provides the current relative weight and a description of each trait in the breeding goal for NR.

All of the EBV in the estimation were standardized to a standard deviation of 7. The mean EBV for each trait for all the sires of the cows on a farm was constructed by using the weighted average for each farm and year, weighted by the number of feeding days. Feeding days are the number of days per year that a cow is in active production. Cows with no registered sires were omitted from the analysis because their number was very small, and no good approximation exists for the actual EBV of unregistered sires. This is analogous to replacing them with the expected EBV of the respective herd.

Extreme values were filtered from the data before analysis. The original data set included 9,006 observations, whereas the filtered data set included 8,617 observations; less than $5 \%$ of the observations were omitted. On average, each farm was included in the analysis for a period of $2.8 \mathrm{yr}$.

\section{RESULTS}

The estimated economic values from function [13] evaluated at the point of centralization for input and output prices (average prices), together with their $t$ values, are reported in Table 2 . The focus in this study was the effect that selective breeding for the different traits has on farm profit. Seven traits have significant economic values, all of which, as expected, are positive. The traits with the largest effects on profits are milk, followed by udder, meat, mastitis resistance, and temperament. The farm-specific random effect was 0.10 , with an associated asymptotic $z$-value of 34.75 and $P$ $<0.001$. This indicates substantial farm heterogeneity. 
Table 1. Relative weights and characterization of the trait or index in the breeding goal for traits included in the breeding goal for Norwegian Red

\begin{tabular}{lcl}
\hline Trait or index & $\begin{array}{c}\text { Relative } \\
\text { weight for } \\
\text { Norwegian Red }\end{array}$ & \multicolumn{1}{c}{ Characterization of the trait or index } \\
\hline Milk & 24 & Combined index: protein, fat, and milk yield \\
Meat & 9 & Carcass value, young bull \\
Other diseases & 3 & Milk fever, ketosis, and retained placenta \\
Stillbirths & 1 & Paternal and maternal \\
Calving difficulties & 1 & Maternal \\
Mastitis resistance & 22 & Frequency (treatments) of clinical mastitis in first, second, and third lactation \\
Fertility & 15 & Female fertility for heifers and first-lactating cows \\
Temperament & 4 & Cehavior of cows when milked, recorded as extra calm, normal, uneasy \\
Legs & 6 & Combined index: rear leg, side view; rear leg, rear view; foot angle; and hoof quality \\
Udder & 15 & attachment, fore and rear udder attachment, udder support, and teat length \\
& &
\end{tabular}

The model in [15] was further used to test whether the EBV have no jointly significant effect on profits. This joint test resulted in an $F$-statistic of 12.14 , with 60 and 5,274 degrees of freedom and an associated $P<$ 0.001 . This was a clear rejection of the hypothesis. A test for profit neutrality, that is, that selective breeding only generally improves productivity and does not specifically affect some inputs and outputs, was also carried out with $F$-statistic equal to 2.75 , with 50 and 5,274 degrees of freedom and a $P<0.001$. This served as a clear rejection of profit neutrality. Because the number of parameters in the translog was quite large, it was of interest to test whether a simpler model could adequately fit the data. One such simple model is the nested Cobb-Douglas profit function. The Cobb-Douglas function involves no interaction effects, so this hypothesis also suggests profit neutrality. The $F$-statistic for this test was 3.97, with 65 and 5,274 degrees of freedom and with a $P<0.001$. This provides a clear rejection of the Cobb-Douglas form in favor of the more complex, but also more flexible, translog model. The economic values estimated with the Cobb-Douglas function are reported in Table 3.

Table 4 presents the relative weights currently used by Geno compared with optimal economic weights cal-

Table 2. Economic values (change in profits in Norwegian crowns for an overall increase in EBV of a herd), for the translog model with SE, $t$-values, and $P$-values

\begin{tabular}{lrrrr}
\hline EBV effect & Estimate & $\mathrm{SE}$ & $t$-value & $P$-value \\
\hline Milk & 2,323 & 241.2 & 9.63 & 0.000 \\
Meat & 1,712 & 286.6 & 5.98 & 0.000 \\
Other diseases & -552 & 314.9 & -1.75 & 0.080 \\
Stillbirths & -85 & 310.0 & -0.27 & 0.784 \\
Calving difficulties & 524 & 321.7 & 1.63 & 0.103 \\
Mastitis resistance & 1,704 & 284.7 & 5.99 & 0.000 \\
Fertility & 964 & 241.6 & 3.99 & 0.000 \\
Temperament & 1,430 & 312.5 & 4.58 & 0.000 \\
Legs & 633 & 286.9 & 2.21 & 0.027 \\
Udder & 2,143 & 319.7 & 6.70 & 0.000 \\
\hline
\end{tabular}

culated from the economic values presented in Table 2 . This was done to facilitate comparison with the weights currently used by Geno. The test results shown are $t$ tests for the hypothesis that the estimated weights are equal to the current weights. The economic weights are calculated as the percentage contribution of each trait to the overall effect of all the EBV on profit, as reported in Table 2.

Table 4 shows a similarity between the current weights and our estimated optimal economic weights, indicating the appropriateness of the diversified breeding goals. The results further corroborate the large weights Geno has placed on traits such as milk, udder, mastitis resistance, and fertility. However, the hypothesis that the optimal economic weight for the study period was equal to the current weights was rejected by a pooled hypothesis ( $F$-value of 4.80 and $P$-value of $<0.001$ ). It was also rejected for each trait, except for milk, stillbirth, calving difficulties, legs, and udder.

\section{DISCUSSION}

There are significant differences between the estimated optimal economic weights and the current relative weights used by the breeding organization Geno.

Table 3. Economic values (change in profits in Norwegian crowns for an overall increase in EBV of a herd) for the Cobb-Douglas model with SE, $t$-values, and $P$-values

\begin{tabular}{lrrrr}
\hline EBV effect & Estimate & $\mathrm{SE}$ & $t$-value & $P$-value \\
\hline Milk & 2,273 & 221.9 & 10.25 & 0.000 \\
Meat & 1,761 & 264.8 & 6.65 & 0.000 \\
Other diseases & -516 & 289.7 & -1.78 & 0.075 \\
Stillbirths & -253 & 283.0 & -0.89 & 0.372 \\
Calving difficulties & 721 & 300.3 & 2.40 & 0.016 \\
Mastitis resistance & 1,614 & 264.1 & 6.11 & 0.000 \\
Fertility & 789 & 221.4 & 3.57 & 0.000 \\
Temperament & 1,431 & 291.2 & 4.91 & 0.000 \\
Legs & 695 & 267.6 & 2.60 & 0.009 \\
Udder & 2,281 & 296.4 & 7.70 & 0.000 \\
\hline
\end{tabular}


Table 4. The weights of the current breeding index used by Geno ${ }^{1}$ and the estimated optimal economic weights, ${ }^{2} t$-values, and $P$-values of the hypothesis that the true weights are equal to the current economic weights

\begin{tabular}{|c|c|c|c|c|}
\hline Effect & $\begin{array}{c}\text { Current } \\
\text { Geno } \\
\text { weight }\end{array}$ & $\begin{array}{c}\text { Estimated } \\
\text { optimal } \\
\text { economic } \\
\text { weight }\end{array}$ & $t$-value & $P$-value \\
\hline Milk & 24 & 22 & -1.11 & 0.266 \\
\hline Meat & 9 & 16 & 2.58 & 0.010 \\
\hline Other diseases & 3 & -5 & -2.78 & 0.006 \\
\hline Stillbirths & 1 & -1 & -0.62 & 0.534 \\
\hline Calving difficulties & 1 & 5 & 1.29 & 0.196 \\
\hline Mastitis resistance & 22 & 16 & -2.36 & 0.019 \\
\hline Fertility & 15 & 9 & -2.71 & 0.007 \\
\hline Temperament & 4 & 13 & 3.19 & 0.001 \\
\hline Legs & 6 & 6 & -0.05 & 0.959 \\
\hline Udder & 15 & 20 & 1.64 & 0.102 \\
\hline
\end{tabular}

${ }^{1}$ Geno (Hamar, Norway).

${ }^{2}$ Based on the economic values in Table 2.

Results from the current study suggest that Geno should reduce its focus on other diseases, mastitis resistance, and fertility but increase it on meat and temperament. This would result in increased profits to the farmers.

Economic theory predicts that the optimizing behavior of the farmer will cause adjustments in levels of variable inputs and output in response to a genetic trait change. This has been argued by Amer and Fox (1992) and Amer et al. (1994) as well as in this paper. The clear rejection of profit-neutral effects in this study indicates that the reoptimization, argued by Amer and Fox (1992) and Amer et al. (1994), occurs on Norwegian dairy farms. It therefore seems that Norwegian farmers are profit maximizing. A model based directly on the production function, as a profit equation model, will not give accurate estimates of the effects of breeding on profits for profit-maximizing farmers because it neglects the indirect effects of selective breeding on profits, as described above.

Any comparison of the study's findings between breeds is difficult. Breeds and breeding goals vary considerably; natural conditions, as well as the prices of inputs and outputs, vary among countries. It is therefore likely that different conditions result in different economic values. Further, measurement units differ. Here the economic value is defined in terms of Norwegian crowns $[$ NOK $100=$ EUR $12.65=$ US $\$ 17.23$, September 6, 2007 (www.oanda.com)], for a unit increase in the farms' average breeding index per farm per year. Other studies of economic values for dairy cattle have defined the economic values as monetary unit per trait unit per cow per year (Vargas et al., 2002; Kulak et al., 2004), or monetary unit per unit of genetic increase of the trait (St-Onge et al., 2002).
The estimates for economic values from the translog profit function and the Cobb-Douglas profit function were quite similar, even though the Cobb-Douglas form was statistically rejected as adequately describing the true relationship. It therefore seems that the estimated economic values are quite robust against the model definition, which facilitates their practical use. The hypothesis of profit neutrality and a simpler Cobb-Douglas relationship were both rejected. It therefore appears that the complexity of the function is justified by its improved fit to the observed data.

The economic values presented here were estimated by using historical data. Their application in current breeding must rely on the assumption that future profit changes attributable to changes in EBV are similar to historical ones. However, the current model allows changes in prices (e.g., increases in the price of concentrate feed) to be taken into account when evaluating current economic values. It is therefore possible to take predictable changes in input and output prices into account when determining future economic values.

The proposed method of evaluating the economic effects of breeding programs requires a rich and reliable data set of farm-level data. In this study, we used Norwegian data that were collected for many years by the breeding organization and the dairy cooperatives. Because the lack of such information clearly prevents this type of ex post evaluation, it is in the interests of breeding companies to facilitate and encourage the collection of suitable records.

\section{CONCLUSIONS}

The main objective of this study was to illustrate how farm-level production and economic data, together with $\mathrm{EBV}$, can be used to evaluate and verify the economic effects of improvements in animals. Based on a fairly rich farm-level panel data set, estimations were conducted on the effects of selective breeding on profits. The results clearly indicate that the Scandinavian tradition, with a relatively broadly defined breeding goal, is profitable for farms. In fact, of the 10 traits examined, 7 significantly improved profits.

Estimation of economic values of animal traits from EBV at the farm level demands a reliable data set. It should cover a large proportion of farmers, with economic and genetic data available across several years.

\section{ACKNOWLEDGMENTS}

This study was part of a strategic institute program financed by The Research Council of Norway (Oslo, Norway), grant no. 143045/140 (Future Animal Breeding Goals). The authors gratefully acknowledge the data 
contributions of TINE (Oslo, Norway), the Norwegian Cow Recording System (Ås, Norway), and Geno (Hamar, Norway).

\section{REFERENCES}

Amer, P. R., and G. C. Fox. 1992. Estimation of economic weights in genetic improvement using neoclassical production theory: An alternative to rescaling. Anim. Prod. 54:341-350.

Amer, P. R., G. C. Fox, and C. Smith. 1994. Economic weights from profit equations: Appraising their accuracy in the long run. Anim. Prod. 58:11-18.

Binswang, H. P. 1974. Measurement of technical change biases with many factors of production. Am. Econ. Rev. 64:964-976.

Brascamp, E. W., C. Smith, and D. R. Guy. 1985. Derivation of economic weights from profit equations. Anim. Prod. 40:175-180.

Chambers, R. G. 1988. Applied Production Analysis: A Dual Approach. Cambridge University Press, New York, NY.

Christensen, L. R., D. Jorgensen, and L. J. Lau. 1973. Transcendental logarithmic production frontiers. Rev. Econ. Stat. 55:28-45.

de Vries, A. G. 1989. A model to estimate economic values of traits in pig breeding. Livest. Prod. Sci. 21:49-66.

Hazel, L. N. 1943. The genetic basis for constructing selection indexes. Genetics 28:476-490.
Huffman, W. E., and R. E. Evenson. 2001. Structural and productivity change in US agriculture, 1950-1982. Agr. Econ. 24:127-147.

Kerr, W. A. 1984. Selective breeding, heritable characteristics and genetic-based technological change in the Canadian beef cattle industry. West. J. Agr. Econ. 9:14-28.

Kulak, K., H. M. Nielsen, and E. Strandberg. 2004. Economic values for production and non-production traits in Nordic dairy cattle populations calculated by stochastic simulation. Acta Agric. Scand., Sect. Anim. Sci. 54:127-138.

McArthur, A. T. G. 1987. Weighting breeding objectives-An economic approach. Pages 170-187 in Proc. Sixth Ann. Conf. Aust. Assoc. Anim. Breeding and Genetics, Perth, Western Australia.

Melton, B. E., W. Arden Colette, and R. L. Willham. 1994. Imputing input characteristic values from optimal commercial breed or variety choice decisions. Am. J. Agr. Econ. 76:478-491.

Melton, B. E., E. O. Heady, and R. L. Willham. 1979. Estimation of economic values for selection indices. Anim. Prod. 28:279-286.

Smith, C., J. W. James, and E. W. Brascamp. 1986. On the derivation of economic weights in livestock improvement. Anim. Prod. 43:545-551.

St-Onge, A., J. F. Hayes, and R. I. Cue. 2002. Economic values of traits for dairy cattle improvement estimated using field-recorded data. Can. J. Anim. Sci. 82:29-39.

Vargas, B., A. F. Groen, M. Herrero, and J. A. M. Arendonk. 2002. Economic values for production and functional traits in Holstein cattle of Costa Rica. Livest. Prod. Sci. 75:101-116. 